\title{
Reinforcing Communication Skills through Participation in a Team-based Weekly Innovation Challenge
}

\section{Mr. Federico Garcia Lorca, Saint Louis University, Parks College of Eng.}

Federico Garcia Lorca is pursuing a $\mathrm{PhD}$. in Aerospace Engineering with his research focusing on entrepreneurial engineering in higher education. Currently Federico is involved in the design of innovation challenges outside the classroom.

\section{Dr. Daniel M. Ferguson, Purdue University, West Lafayette}

Daniel M. Ferguson is the recipient of four NSF awards for research in engineering education and a research associate at Purdue University. Prior to coming to Purdue he was Assistant Professor of Entrepreneurship at Ohio Northern University. Before assuming that position he was Associate Director of the Inter-professional Studies Program and Senior Lecturer at Illinois Institute of Technology and involved in research in service learning, assessment processes and interventions aimed at improving learning objective attainment. Prior to his University assignments he was the Founder and CEO of The EDI Group, Ltd. and The EDI Group Canada, Ltd, independent professional services companies specializing in B2B electronic commerce and electronic data interchange. The EDI Group companies conducted syndicated market research, offered educational seminars and conferences and published The Journal of Electronic Commerce. He was also a Vice President at the First National Bank of Chicago, where he founded and managed the bank's market leading professional Cash Management Consulting Group, initiated the bank's non credit service product management organization and profit center profitability programs and was instrumental in the breakthrough EDI/EFT payment system implemented by General Motors. Dr. Ferguson is a graduate of Notre Dame, Stanford and Purdue Universities and a member of Tau Beta Pi.

\section{Dr. Sridhar S. Condoor, Saint Louis University, Parks College of Eng.}




\section{Reinforcing Communication Skills through Participation in a Team-based Weekly Innovation Challenge}

Introduction

The Weekly Innovation Challenge (WIC) is an opportunity for students, staff and faculty to engage in competition while honing their ability to think, act and pitch new ideas. WIC leaders plan and run the competition to help participants learn important lessons in team collaboration, communication, innovation and opportunity recognition. These four themes constitute the fundamental learning objectives envisioned for WICs.

This team-based competition has been an ongoing event at the engineering school of a private Midwestern university for the past three years. WIC leaders believe that participants greatly benefit from improved communication in terms of behaviors and resulting skills are the focus of this paper.

Communication has been identified by business executives as one of the top skills needed by professionals in the current workplace ${ }^{1}$. Professionals with good oral and written skills, as well as presentation and listening proficiency are more likely to be hired and lead successful careers. ABET's accreditation criterion for student outcomes include the "ability to communicate effectively" 2 .

The WIC Competition

Once a week participants from all majors ranging from the college of arts and sciences to law school come to the engineering school where they sign up in teams of three members to compete in a one hour long challenge. To ensure a multidisciplinary experience, participants in a team must be from different majors. The WIC is kicked off with a challenge statement containing the criteria for winning the challenge. Then, teams design, build and deliver - if necessary - their solution for that week's challenge.

At the end of each competition, ideas are evaluated and the winning team is determined. Winning team receive a prize of $\$ 100$ per member plus a T-shirt with the WIC logo and the words "Winner" on the back. Also, all participants are encouraged to submit a written reflection. The author with the best reflection wins a $\$ 100$ prize, regardless if such author was also part of the winning team for the day's challenge. Furthermore, participants can participate in as many WIC competitions as they wish and in the past 3 years many teams have returned multiple times.

Challenge Leaders take responsibility for creating every WIC competition, determining the necessary materials to carry it out successfully and redacting the challenge statement. The statements must be short texts of less than 100 words containing all the information WIC participants need. Challenge leaders also welcome participants to the competition, provide teams with sign up forms and answer any questions both before and during the competition.

Types of WIC Competitions

The challenges can be classified into three types: i. Build and prototype tests (build), ii. Develop and pitch of ideas (pitch) and iii. Nurture curiosity (curiosity) challenges. Each 
type has a goal and a set of evaluation criteria that requires teams to deliver different solutions depending on the challenge type. However, all challenge types require participants to conceive innovative ideas. The difference is on what they do with the ideas. During a build and prototype test challenge, teams prototype their solution with the given supplies to fulfill the challenge's goals. These goals prompt teams to think about trade-offs and optimization. Examples of build and prototype test challenges range from building a bridge that spans a certain length while withstanding the heaviest weight to catapults that project a baseball as far as possible while minimizing the weight of the catapult itself.

Develop and pitch of ideas challenges focus on selling the ideas. Teams spend their time both creating an idea and planning the delivery of it to the judges. Teams can prototype their ideas if they think it will help in their presentations. Most teams draw sketches and diagrams, devoting most of their time developing their solution and preparing the perfect pitch. Examples of pitch challenges are "Pitch for America Challenge", where teams simulate being part of an American trade delegation trying to convince Indian investors to invest in American manufacturing and the "Future of Education Challenge" where teams presented their vision of higher education for the next decade.

Finally, nurture curiosity challenges bring participants ability to observe and incorporate ideas. One curiosity challenge uses geoguessr to show participants the importance of attention to detail. Teams must guess where they are in the world, with the closest guess winning the round. Details such as type of construction, traffic patterns, road signs, language on the signboards and terrain are crucial to identify where they are.

\section{Research questions}

This study attempts to assess the communication behaviors displayed by WIC participants in order to address two research questions:

Are WIC participants learning or reinforcing their communication skills?

What types of WIC experiences best promote improved communication behaviors?

\section{Research Design}

Over the past two academic years 68 participants submitted 146 reflections. These reflections span over 50 different challenges, with all three challenge types present in different proportions. A random sample of 45 reflections was selected for this study, 15 reflections for each challenge type. These reflections were examined using a qualitative study methodology and coded using the Written Communication Value Rubric developed by the Association of American Colleges and Universities ${ }^{3}$ and the Kolbe A Index for measuring instinctive methods of operation ${ }^{4}$. Six codes were used to examine how individuals interacted within the team, shared their emotions and championed their own contributions.

Table 1: Code Definitions

\begin{tabular}{|c|l|}
\hline Code & \multicolumn{1}{|c|}{ Description } \\
\hline Engages & $\begin{array}{l}\text { Mentions work with team members, how team members reacted to } \\
\text { plans, ideas, feedback or comments, describes the way the team } \\
\text { performed with each member }\end{array}$ \\
\hline Organizes & Organizes thoughts from start to finish in a concise manner. \\
\hline
\end{tabular}




\begin{tabular}{|c|l|}
\hline Explains & $\begin{array}{l}\text { Uses examples and definitions to support ideas, design approaches or } \\
\text { problem-solving, describes team problem solving processes, how a } \\
\text { solution was reached, the reasoning or logic behind actions }\end{array}$ \\
\hline Shares & $\begin{array}{l}\text { Describes emotions, feelings, moods, fears, hopes, expectations } \\
\text { regarding oneself and/or team members, reveals personal preference } \\
\text { on topics, behaviors, decisions, plans, designs and solutions }\end{array}$ \\
\hline States Purpose & $\begin{array}{l}\text { Directly describes the purpose of the WIC, its objectives or goals, } \\
\text { describes the team's solution or approach without details of the } \\
\text { process }\end{array}$ \\
\hline Promotes & $\begin{array}{l}\text { Describes ideas or outputs to increase visibility with the team, } \\
\text { encourages the team to agree in the way decisions were made, } \\
\text { positions the solution as the best possible output }\end{array}$ \\
\hline
\end{tabular}

To verify the qualitative analysis of the reflections a focus group session was conducted with five regular WIC participants at the end of the 2013-14 academic year. A professional focus group facilitator conducted the focus group session. In addition, a strength coding study and an inter-rater test was conducted to guarantee coding consistency ${ }^{5,6}$.

Table 2: Strength Rubrics

\begin{tabular}{|c|c|}
\hline $\begin{array}{c}\text { Rubric for assessing the } \\
\text { strength of a reflection quote. }\end{array}$ & $\begin{array}{c}1 \text { - Vaguely refers to the communications behavior } \\
\text { definition }\end{array}$ \\
\cline { 2 - 2 } $\begin{array}{c}\text { Strength can be positive or } \\
\text { negative in assessing student } \\
\text { behavior. }\end{array}$ & $\begin{array}{c}\text { Explicit or implicitly refers to one or more points in the } \\
\text { communications behavior definition }\end{array}$ \\
\cline { 2 - 2 } $\begin{array}{c}5 \text { - Explicitly refers to one or more points in the } \\
\text { communications behavior definition and how they were } \\
\text { applied. }\end{array}$ \\
\hline
\end{tabular}

Analysis

Analysis of all 45 reflections yielded similar results across all three challenge types of (Table 3). Regardless of the type of competition participants always exhibited similar levels of communication behavior. Even if slight differences can be noted. Codes "Explains" and "Shares" have the highest total count and are clearly more common in the analyzed sample.

Table 3: Reflection Coding Results

\begin{tabular}{|l|c|c|c|c|c|c|c|}
\cline { 2 - 8 } \multicolumn{1}{c|}{} & Engages & Explains & Promotes & Shares & States Purpose & Well Organized & Total \\
\hline Build & 10 & 45 & 8 & 22 & 16 & 5 & 106 \\
\hline Pitch & 11 & 36 & 4 & 26 & 9 & 3 & 89 \\
\hline Curiosity & 11 & 30 & 2 & 19 & 14 & 5 & 81 \\
\hline
\end{tabular}

This analysis suggests participants first promote their ideas by supporting them with facts and logic and by informing their team members of their feelings. These two behaviors (supporting and sharing) complement each other: while championing ideas can be a selfpromoting effort ${ }^{7}$, sharing emotions - especially when positive - greatly recognizes the importance of the team ${ }^{8}$. Since the analyzed reflections were chosen at random, this behavior cannot be attributed to a winning or losing strategy. 
The results also highlighted a low frequency of occurrence for four of the six communication behaviors. This low frequency is interesting in the case of the communication behavior "Promotes". As defined in Table 1, the communication behavior "Promotes" is rooted in the "Explains" behavior, which occurs at a high frequency. However, "Promotes" carries a task-oriented component as the participant is positioning a solution as the optimal goal as opposed to solely trying to share it. Previous studies have shown that task-focused discussions as low-quality team member exchanges and ultimately members associate these discussions with negative emotions ${ }^{7}$. The lack of "Promotes" instances could therefore be seen as an indicator of good teamwork interactions.

The median word count of all samples was approximately 300 words with the shortest reflection being 128 words and the longest 1410 words. The average word count was approximately the same when grouping the samples by build and prototype test, develop and pitch of ideas and nurture curiosity types. The average number of communication behaviors instances was also fairly uniform: build had an average of seven communication behaviors instances per reflection, pitch average six communication behaviors instances and curiosity five instances per reflection.

After analyzing all reflection samples the focus group session was analyzed for the same communications behaviors ${ }^{3,4}$. Table 4 shows the results of the focus group analysis process. The number of communication behavior instances for the focus group session follows similar trends to the results found for the written reflections. Student participants who submitted reflections show the same trends as the five WIC participants that volunteered for the session. Also no communication behavior instances were found for "States Purpose" and "Well Organized" in the focus group data.

Table 4: Focus Group Coding Results

\begin{tabular}{|c|c|c|c|c|c|c|}
\hline Engages & Explains & Promotes & Shares & States Purpose & Well Organized & Total \\
\hline 5 & 23 & 6 & 14 & 0 & 0 & 106 \\
\hline
\end{tabular}

A strength analysis of the reflection analysis was performed to ensure quality and reliability of the qualitative data analysis. There were a total of 233 quotes selected from the reflection samples. They included all codes and all three levels of strength described in Table 2. It was concluded that there were an appropriate level of strong quotes. Table 5 contains examples of quotes from the reflection samples representing strength " 5 ".

Table 5: Strength Study for Reflection Samples

\begin{tabular}{|c|c|}
\hline Code & Quote \\
\hline \multirow{2}{*}{ Engages } & $\begin{array}{l}\text { "We managed to quickly brainstorm a wide variety of ideas and even create } \\
\text { three working models" }\end{array}$ \\
\hline & $\begin{array}{l}\text { "The group discussed and decided that we weren't really sure on which idea } \\
\text { would actually work" }\end{array}$ \\
\hline \multirow{2}{*}{ Explains } & $\begin{array}{l}\text { "The key to a successful design is to imitate its use in your mind, construct the } \\
\text { design, and modify it for maximum efficiency" }\end{array}$ \\
\hline & $\begin{array}{l}\text { "We quickly ran into a strength problem due to the fact that the connection } \\
\text { points were only held together by glue." }\end{array}$ \\
\hline \multirow[b]{2}{*}{ Promotes } & $\begin{array}{l}\text { "Our idea to protect our towers was to scatter them so that it would take at least } \\
\text { three shots to get all three down." }\end{array}$ \\
\hline & $\begin{array}{l}\text { "Weight and balance is key for flugtag. When it is top heavy, the glider dives } \\
\text { and when there is too much weight in the back, the glider will stall and tend to } \\
\text { flip backwards and then dive bomb." }\end{array}$ \\
\hline
\end{tabular}




\begin{tabular}{|c|c|}
\hline \multirow{2}{*}{ Shares } & $\begin{array}{l}\text { "Frustration definitely overcame me as I could not put anything worthwhile } \\
\text { together out of just pasta noodles and life savers" }\end{array}$ \\
\hline & $\begin{array}{l}\text { "It was extremely fun to get to see everyone thought process and by the end, } \\
\text { the challenge didn't seem like a challenge" }\end{array}$ \\
\hline $\begin{array}{l}\text { States } \\
\text { Purpose }\end{array}$ & $\begin{array}{l}\text { "The trick was to answer the question asked of the group without being the one } \\
\text { holding the baton when the timer went off. Having the baton meant losing a } \\
\text { point while reaching the right answer meant gaining a point" }\end{array}$ \\
\hline
\end{tabular}

Finally, further evidence of the introduction or reinforcement of communication behaviors is shown in Table 6. More than half of the random sample of reflections used in this analysis contains explicit references to learning experiences, remarks by the reflection authors in regards to the learning process taking place as a result of participating in WIC.

Table 6: Reflection Quotes Regarding WIC experiences

\begin{tabular}{|l|}
\hline \multicolumn{1}{|c|}{ Quote } \\
\hline "Since we had worked with each other before (in other challenges), we knew \\
how to function better as a group, and we communicated better. We were able \\
to carry out our ideas faster" \\
\hline "This challenge made me realize that communication and understanding the \\
consumer is key; so, as engineers, when we are designing our products we \\
should always keep that in the back of our mind" \\
\hline "This is a great lesson to take away from the challenge. [...] When I am an \\
engineer and I think I have a great idea that is worth pursuing, I need to convey \\
that message. With a good pitch, that grabs the attention of my boss, I can \\
display why it is worth it for him to invest in me." \\
\hline "As a result of this week's Innovation challenge, I now recognize that I may \\
not be able to do everything well, but there is no shame in calling on a friend if \\
I need help." \\
\hline "[...] It is times such as these that the lesson learned from today's innovation \\
challenge can be applied. Had this employee found the courage and the time to \\
present his idea, [it] could have significantly changed the factory. I will always \\
keep in mind that moment [...] so that one day at my work place I will find the \\
courage to express my projects, goals, and ideas" \\
"I learned a lot during this challenge. The main takeaway is this: It's \\
impossible to pitch an idea to investors if you can't even pitch the idea to your \\
own team."
\end{tabular}

Findings

Weekly Innovation Challenge competitions introduce or reinforce communication behaviors for all participants. Significant evidence of all six communication behaviors was found in reflection and focus group data. While some reflection samples did not have instances of all the communication behaviors, a range of between five and seven communication behavior instances was found per reflection.

In addition, communication behaviors were present while teams competed in all of the three fundamental types of WIC. Regardless of WIC type - build, pitch or curiosity communication behaviors instances ranged from 5-7 instances. Finally, focus group participants provided corroborating evidence of communication behavior instances. 


\section{Conclusion}

There is significant evidence that students have either discovered how to communicate more effectively in a multidisciplinary team or have strengthened their communication skills by participating in a WIC. Moreover, each type of Weekly Innovation Challenge - build, pitch, and curiosity -reinforces one or more of the six types of communication behaviors.

\section{Recommendations}

In the future implement pre-post surveys identifying communication behaviors to better measure the footprint of WICs in terms of communication learning. Also, increase the number of reflections collected to improve the reliability of the communication behavior analysis and potentially uncover learning trends. Distributing small communication behavior reflection guidelines to students at the beginning of a Weekly Innovation Challenge may also help them learn communication behaviors.

\section{Limitations}

The quality of the data gathered for this study depends on the student's ability to convey his or her experiences in a written format. It could also be the case that students are uncertain as to what is expected of their written reflection. In the past WIC leaders encouraged participants to submit a written reflection but no guidance was given as to what the reflection had to be about. Some authors of the sample reflections used for this study used their reflection as an opportunity to suggest improvements for WIC, present ideas for future challenges or express personal preference for one type of WIC competition over another.

The author's personal skills at communication in a team environment also potentially biased the analysis process.

\section{References}

[1] Robles, Marcel M. (2012). Executive Perceptions of the Top 10 Soft Skills Needed in Today's Workplace. Business and Professional Communication Quarterly December 2012 vol. 75 no. 4 453465

[2] ABET (2015) Criteria for Accrediting Engineering Programs 2015 - 2016. General Criterion 3. Student Outcomes. Retrieved from: http:/www.abet.org/eac-criteria-2015-2016/

[3] Association of American Colleges \& Universities. (2010). Written Communication Value Rubric. Retrieved from: http:/www.aacu.org/value/rubrics/written-communication

[4] Kolbe Corp. (2015). Kolbe A Index Assessment Tool. Retrieved from: http://www.kolbe.com

[5] Leydens, J., Moskal, B., \& Pavelich, M. (2004). Qualitative Methods Used in the Assessment of Engineering Education. Journal of Engineering Education, 93(1), 65-72.

[6] Patton, M. (2002). Qualitative research and evaluation methods (3rd ed.). Thousand Oaks, CA: Sage Publications. 
[7] Shane, S., Venkataraman, S., \& MacMillan, I. (1995). Cultural Differences in Innovation Championing Strategies. Journal Of Management, 21(5), 931-952.

[8] Tse, H., Dasborough, M. (2008). A Study of Exchange and Emotions in Team Member Relationships. Group \& Organization Management, 33(2), 194-215. 